\title{
The Application of Graduation in Political Speech
}

\author{
Xiaoyan Fan \\ Shanxi Normal University, Linfen, Shanxi, China
}

\begin{abstract}
In this paper, the graduation system in appraisal theory is combed, and the development and theoretical origin of the graduation system are discussed. The development of graduation system can be divided into three stages: embryonic stage, develop stage and mature stage. The graduation system embodies three important thoughts: the thought of grading, the thought of strengthening, the thought of vagueness. They are interrelated and have a broad theoretical basis. Tracing the development of the graduation system and its theoretical sources will help us to further to understand and improve the graduation system, and better apply the evaluation theory to discourse analysis, language teaching and other research fields. Political speech is a written oral speech that reflects the value of the discourse information conveyed by the speaker by means of explicit or implicit evaluation. These value judgments and their evaluation resources also reflect the speaker's position, views and attitudes. In the appraisal theory, the speaker uses the graduation system to increase the intensity of discourse. This paper proves that the graduation to analyse the special political speech is useful, it enriches the research on political speech and provides valuable inspiration for Chinese and foreign scholars in the relevant academic writing.
\end{abstract}

Index Terms-appraising, graduation, political speech

\section{INTRODUCTION}

Appraisal Theory is an interpersonal functional category developed by Professor Martin and his colleagues in the Department of Linguistics at the University of Sydney since the mid-1980s. It is used to show how we use language to express or communicate attitudes and emotions. This theory starts with appraising vocabulary and promotes the study of interpersonal meaning within the framework of discourse semantics. It fills the gap between classical systemic functional linguistics which focuses on the study of interpersonal meaning from clause grammar and neglects the study of lexical resources in discourse. Appraisale theory is divided into three subsystems: Attitude, Engagement, and Graduation. Among them, the position of the graduation system is very special. It runs through the whole appraisal system and provides graded resources for the attitude system and engagement system. "We can say that the attitude system and engagement system belong to the category of graduation," he said. But the meaning of grading is essentially different (Martin \& White, 2005, p. 136).

Appraisal is an indispensable feature of any text, which is manifested in the semantic structure of the text. Public speaking especially the political speech is the best material for discourse analysis because of its epochal, social and scientific nature. Having an appraisal means interaction and negotiation between the speaker and the listener, and the speaker tries to get the reader to accept his comments. In the graduation system of appraisal theory, focus and linguistic potential can be explored from two aspects at the same time, that is, softening, reduction and sharpening, raising, representing different semantic values of the same category. The author usually realizes a political speech by changing the semantic value of the graduation, sharpening one aspect of the event with a high semantic value, and softening the event with a low semantic value on the other hand. In political speech, which emphasizes objectivity, authenticity, tightness and rationality, the accuracy of the author's words is very high, so it is very important to choose the appropriate semantic value.

\section{LITERATURE REVIEW}

As the early 1990s, Martin systematically explained the generality of grading. Later, the concept of grading was gradually incorporated into the appraisal system, which constituted a subsystem-graduation system. Generally speaking, the development of graduation category has experienced three stages.

\section{A. The Embryonic Stage}

This stage took place in the early 1990s. The representative worker were Martin (1992a) .Martin inherited the viewpoint of Sapir (1944) and considered that the significance of graduation was universal, and put forward the concept of grading system for the first time. Martin pointed out that The grading system is organized according to degree, evaluation and attitude, usually divided into three degrees, high, medium and low. The classification system is embodied in clauses, noun phrases and verb phrases. Martin often used lexis to express different degrees of attitude, such as bad-horrible-appalling,good-great-fantastic,walk-stroll-saunter,cry-scream-howl. In these words of attitude, the extreme examples are the swearing and the taboo word, for example, the curse Jesus that god-damn bastard is un-bloody-believable. Taboo words, such as penis-prick, breast-tit, urinate- piss. 
The graduation category in its infancy is only a simple classification system, which classifies the interpersonal meaning of clauses, noun phrases, verb phrases and some words from the perspective of grammatical structure. This classification has a relatively strong arbitrariness, each subsystem is usually divided into three levels: high, medium and low. It can be seen that on the one hand the graduation category at this stage still emphasizes the interpersonal meaning of different values of the grammar (modality) of small sentences; on the other hand it begins to pay attention to the graduation meaning embodied by lexical resources in discourse. Martin had not formed a complete attitude system and engagement system at this time, because the category of graduation in the embryonic stage was outside the appraisal system and did not form a part of the whole appraisal system.

\section{B. The Develop Stage}

Martin \& Rose (2003) promoted the study of appraisal theory as an interpersonal meaning system and incorporated it into Martin's four discourse systems (1992b). In this way, five discourse systems were formed: appraisal, ideation, conjunction, identification and periodicity, further promoted the development of textual semantics. Martin \& Rose (2003) divided the appraisal theory about three existing subsystems: attitude, engagement and graduation. Among them, the graduation system is further divided into force and focus. The potential is used to strengthen or weaken the meaning, which can be divided into raise and lower. In terms of square expression, the force can be divided into intensifiers and attitudinal lexis, metaphors and swearing. Focus is the classification of categories that are essentially non-hierarchical, including to sharpen and soften for the tested categories.

Obviously, there is a great change in the category of graduation in the develop stage, it breaks with the excessive reliance upon classical systemic functional linguistics on the analysis of mood and modality at the clause level in order to explore the aspect of interpersonal meaning. Focus on the interpersonal meaning is expressed by lexical resources in discourse, the emphasis is exploring the enhancement or weakening of interpersonal meaning from the perspective of lexical resources themselves.

\section{The Mature Stage}

Martin \& White (2005) discussed in detail the subsystems of appraisal theory and their applications, and further developed and perfected the graduation system. Compared with the first two stages, there are three main changes in the graduation system in this stage. First of all, the status of the graduation system in the whole appraisal system has been clear, and all the attitude significance is scalable. Martin \& White (2005) held that the semantic study of graduation occupied a central position in the appraisal system, the attitude system and engagement system belonged to the category of graduation, but the semantic essences of classification are different. Second, they reintegrated the meaning of the linguistic potential and the subsystem of focus on the graduation system. There are two choices: up-scale and down-scale, which avoid the overlap between the strong / weak and the sharp / soft on the subsystems of force and focus. Finally,they both inherited and developed the specific classification of the graduation system. They still divided the graduation system into two subsystems: force and focus, but abandoned the previous stage of classifying the system purely from grammatical expressions, no longer distinguishing between intensifiers and attitudinal lexis, metaphors and swearing. They used dichotomy to classify the force system from the perspective of the lexical expression of experiential meaning and mode. From the perspective of the empirical meaning of lexical expression, the force is mainly an evaluation of the intensity and the degree of quantity, so it can be divided into two subcategories: intensification and quantification. Intensification is mainly concerned with quality and process,. Quantification is the evaluation of number, mass and extent, in which the extent includes the proximity and the distribution. In terms of expression, the force can be divided into two types: isolating and infusing. The former means that the intensification or quantification of the force is mainly accomplished by adding individual words, and does not depend on other words. For example, happy-very happy; the latter thinks that force is realized by a word itself, which belongs to a certain group of words. These words are relevant, but indicate different degrees of processing, such as contented-happy-joyous.

\section{TheORETICAL SOURCES OF GRADUATION SYSTEM}

Martin absorbs the theory of the multi-disciplinary field and develops the graduation system step by step. In general, there are three important ideas about the graduation system: (1) the thought of grading; (2) the thought of strengthening; (3) the thought of vagueness.

\section{A. The Thought of Grading}

The thought of grading is the core of the differential system. In essence, the grading system is about how to classify the appraisal resources. This thought also runs through the whole development process of the grading system. Martin (1992) inherited and developed Sapir'thought (1944) "the classification of meaning is universal."(p. 96). This paper probes into the grammatical expression of classification and its relationship of interpersonal meaning, and constructs a classification system, thus forming the embryonic form of grading system. Martin \& Rose (2003) inherited the previous idea that an important feature of attitude is that they can be graded. Focus is the classification of things that cannot be graded qualitatively. Martin \& White (2005) reiterated that gradation is not only an important characteristic of attitude 
systems, but also an important characteristic of engagement systems. Thus, the central position of the graduation system in the whole evaluation system is established.

The research on grading has a long history. When Sapir evaluated the characteristics expressed by unit of measure or number, he always directly or indirectly involved the appraisal of classification. He distinguished logical classification, psychological classification and language level. Horn (1972), he introduced the concept of scale, when discussing the semantic features of logical operators in English, grading phenomena is very common to language, not only at the lexical level, but also at the semantic, syntactic and pragmatic levels. Grading studies had been extended to all field of linguistic research.

The graduation system in the appraisal system absorbs the research results of graduation, and introduces the idea of classification into the attitude and engagement resources in the appraisal system, which is used to explain the enhancement or weakening of the meaning in the attitude and engagement subsystems. In addition, Martin further developed the idea of classification and combined it with the concept of cline in systemic functional linguistics. In his view, the grading meanings in the attitude and engagement subsystems are not isolated, they are related to each other to form a continuum, high and low values are the two ends of the continuum, and in the middle of the continuum has various changes. This idea of continuous classification is the theoretical foundation of graduation system. Any category in graduation system can be classified into a continuum, such as the continuum of quantitative, the continuum of process, the continuum of focus, and so on.

\section{B. The Thought of Strengthening}

The thought of strengthening is in the same vein as the thought of grading that mentioned above. Since meanings can be graded, they can be strengthened or weakened. In the graduation system, Martin distinguishes between two types of enhancement: quality and process. The enhancement of quality is mainly to the meaning of adjectives or adverbs, while the process of strengthening is to strengthen the meaning of verbs or modality (possibility, habituation, obligation and tendency). In terms of representation, intensification in graduation system can be divided into isolated type, injection type, reduplication type and metaphorical reinforcement.

Bolinger (1972) systematically explored the intensification of various words of English. He believed that not only adjectives and adverbs are often reinforced in English, but nouns and verbs can also be strengthened. These four types of words are usually reinforced by the intensifier. There are four types of intensifiers: boosters, compromisers, diminishers and minimizers. In addition to degree modifiers, there are other ways of strengthening: rhetorical reinforcement, prosodic reinforcement and word repetition reinforcement. Labov (1984) explored the phenomenon of reinforcement in language from a sociolinguistic point of view. It was believed that the core of social and emotional expression is a linguistic phenomenon, and the reinforcement is a grading feature, which depends on its linguistic expression.

Quirk (1985) promoted the study of the phenomenon of intensification in language, which collectively refers to adjectives or adverbs that have an enhanced or weakened effect on the modified components as intensifiers. Among them, adverb degree modifiers can vary according to the modified components. When modifying adjectives, most adverbs are intensifiers.

The idea of intensification in the graduation system absorbs the research results of the above phenomenon. The enhancement of quality and process in the intensification subsystem refers to the adjectives and adverb and verb mentioned by Bolinger (1972), and the intensifiers in Quirk (1985). In addition, several expressions of reinforcement of graduation system, such as superimposed reinforcement and metaphorical reinforcement, are mentioned in Bolinger (1972) and Labov (1984).

\section{The Thought of Vagueness}

The thought of vagueness is closely related to the thought of graduation mentioned earlier. Because the meaning can be graded, and each grading meaning constitutes a continuum, the boundary between the meanings of each classification is not obvious, and sometimes it is difficult to distinguish. This reflects, in another way, that language is vague and uncertain. The thought of vagueness on the graduation system is mainly reflected in the focusing subsystem. Focus is a graduation system based on prototypicality, which shows that when we use language, we often use some lexical means to obfuscate the boundary of categories and change the typicality of an empirical category. Through the focusing system, the typicality of the empirical category is sharpened or softened, thus being given an attitude meaning, such as, "they don't play real jazz,I'm feeling kind of upset".

The thought of vagueness in graduation system mainly comes from the study of hedging in pragmatics. Zadeh (1965) proposed the concept of vagueness set for the first time, but Lakoff (1972) was the first work in the study of vague language. In this paper, Lakoff first put forward the concept of vague words, which is defined as "some words that make things fuzzy". Since Lakoff (1972), the study of vague language has been greatly developed and widely used in various fields of linguistics, especially in pragmatics and discourse analysis.

The construction of focusing subsystem in graduation system absorbs the research achievements of vague language theory of pragmatics. The focusing system is divided into two sub-systems, that is ascending and decreasing. Ascending is related to the concept of enhancement word put forward by Hyland (2000), while decreasing to embody the idea of "making things have fuzzy characteristics" in vagueness language theory. In terms of expression, the expressions of the 
focusing system refer to the number of vague words of Brown \& Levinsion (1987), the simple vague words of Hyland (1998) and the vague words of Hyland (1998).

\section{Political Speech}

The concept of speech first appeared in the Homer epic. It refers to the public transmission of information, the expression of opinions, the clarification of facts, and the expression of feelings to the audience by means of sound language and corresponding body language in a specific spatio-temporal environment. In order to achieve the purpose of inspiring the audience. It is an artistic social practice, a means to impart knowledge and a powerful tool for social communication. Among them, political speech is a kind of speech which is widely concerned by people. Its speakers mainly expound and comment on international and domestic major events and practical problems from the political point of view. Election speeches, inaugural speeches, reports on government work at all levels, debates, political rallies, diplomatic speeches, military speeches, political and ideological education all belong to political speeches. It is often possible to understand the social culture, traditional customs, historical background and ideology of its speakers and even the countries it represents from political speeches. Political speeches use explicit or implicit evaluation methods to reflect the value judgment on discourse information conveyed by the speaker. These value judgments and their embodiments constitute the evaluation resources of the speech discourse, which in turn reflect the speakers' positions, viewpoints and attitudes. Generally speaking, the functional tone of political speech discourse is mostly persuasive. The speaker's communicative intention is to change the original belief of the audiences and urge them to take some action to realize the intention of persuasion. Therefore, most speech languages have the functions of expression, appeal and infection.

Political speech is a kind of speech that represents certain political position and group interests. The basic characteristics are ideological, policy and strategic. Political speeches are more propaganda than other speeches. It conquers the audience with a clear and firm position, full and eloquent reasoning, and urges the audience to accept and act on the ideas they propagate. Political speeches include campaign speeches, political reports and debriefing speeches. Campaign speech refers to a speech in which a certain organization recommends itself for a position or job by eloquence. A speech outline or draft should be prepared in advance, either in a given order or in the order determined by lot, or in a debate. A campaign speech is actually a kind of self-promotion of a speaker, explaining "he can't do it, I can do it," or "he can do it, I can do it" in a way that argues for it, and induces voters to "vote for me." A political report is a speech made at a meeting on a political issue, that to state one's own political point of view. In our country, people concerned are often organized to listen to political reports, and leaders give speeches on political situation, political principles and policies. And guide relevant personnel to make clear the political direction. In capitalist countries, political reporting is usually made by important figures of political parties, group meetings, or Congress, collectively referred to as speeches. A debriefing speech expresses one's attitude to a person or the public on how to deal with official matters. The content of the speech is clear and clear-cut, with specific implementation methods, often indicating the goals achieved and the results achieved. Leading Western government officials are required to deliver such speeches when they take office. Our government officials and leading cadres at all levels of the Party also make work reports on a certain time and at a certain meeting, which is also a debriefing speech.

\section{The ApPlication of Graduation in Political SpeECH}

Graduation runs through the whole appraisal system, attitude resources and engagement resources can be classified, which mainly to reflect the strong, weak and prominent degree of the speaker's evaluation tone, and can make the speech more freely. Force does not produce new interpersonal meaning, but only increases or reduces the level of appraisal resources, it has two branches: quantification and intensification. The former is measured according to quantity, form and degree, while the latter is measured by quality, process and modality. Focus includes sharpen and soften, which are graduation system based on typicality. The former describes prototype, modified with 'real,genuine', and the latter describes marginalized things, modified with 'sort of,kind of '. The following excerpts from public speeches are selected to illustrate the application of graduation in political speech.

\section{A. The Application of Force}

(1). Billions of people are moving towards modernization with quickened pace. Multiple growth engines have emerged in regions across the world.

(2). As challenges often take on global dimensions, it is more necessary for all countries to take on them cooperatively, turning pressure into motivation and crises into opportunities.

(3). At the same time, we are soberly aware that as a large developing country with 1.3 billion people, China will encounter still greater and tougher challenges on the road to progress.

These several sentences are selected from a major speech by Chinese President Xi Jinping at the Moscow Institute of International Studies, entitled "keeping pace with the times and advancing the trend of world peace and development," to elaborate on China's views on the current international situation, also elaborate China's diplomatic Policy and its position on developing Sino-Russian Relations. 
In example 1, the words "billions of" and "multiple" both denote the number of people, indicating the rapid development of the world, which is China's view of the current world. In example 2, the enhanced form of "more necessary" highlights the need for active cooperation among peoples in the face of global challenges. In example 3 , the specific data of 1.3 billion clearly shows the number of people in China, and the use of the comparative form of "greater and tougher" highlights the magnitude of the challenges facing China. This statement shows that China will face even more difficult problems with its development path, and that it will have to work hard to achieve the goals it has set.

(4). The best hope for peace in our world is the expansion of freedom of all the world. America's vital interests and our deepest beliefs are now one.

(5). Guided by these principles once more, we can meet those new threats, which demand even greater effort, even greater cooperation and better understanding between nations.

The above sentences were taken from the inaugural speeches of two US presidents, Bush and Obama, both of whom described their principles and policies to lead the development of the country and the solutions to the current difficulties encountered by the country.

In his inaugural speech in 2005, Bush emphasized the concept of freedom by using the comparative form "best" and the quantitative word "all", pointing out that the fervent desire for peace can only be attributed to the expansion of freedom from the world. And "vital" is more important than "important" and "significant", so "vital" is also a sign of graduation, it can express the author's attitude and arouse the attention of the audiences. When it comes to Iraq, Obama is calling for even greater efforts, inter-state "even greater" cooperation and greater understanding in response to new threats. The comparative form is also used, which shows that the comparative form is a common means of graduation.

(6). We must reclaim our country's destiny and dream big and bold and daring.

(7).... made up of millions of hard-working men and women who love their country and want a better, brighter future for themselves and for their family.

These sentences from a speech that Trump made after he won the general election in the United States on November 9, 2016.Trump shaped his social image, built relationships with his audience and achieved political goals.

In example 6, "must" is a high-valued modal verb used to reinforce a firm attitude. Through such words, the speech reinforced the language's momentum, demonstrating Trump's determination and his desire to win more civic support. Example 7 describes the desire of the American people for a better and brighter future, which can strengthen the enthusiasm of the audience and ignite public expectations. At the same time, it can also resonate with each other, and enhance the persuasiveness of the speech. Trump has used "millions of" to quantify a large number of supporters in an effort to seek the favor of citizens that have not previously supported him.

(8). That's the future we hope for. That's the vision we share. That's where we need to go forward. That's where we need to go.

(9). It doesn't matter whether you are black or white, Asian or Native American, young or old, rich or poor, able or disabled.

These sentences are selected from Obama's presidential victory speech in 2012. He used a wealth of language appraisal resources to impress and inspire the audience with one or more passionate victory speeches, he tried to close the gap between the audience, to create a positive image among the audience, and to enhance the authority and persuasions of his views. Repetition is a reflection of strengthening resources and means, such as the repeated use of "that's" and "or" by Obama to strengthen feelings, which enhance the authority on their positions and views, reflect their self-confidence and optimism, his advocacies including democracy, equality, progress and other ideas stimulate public enthusiasm and patriotism.

\section{B. The Application of Focus}

(10). There are a lot of speeches, and we've heard lots from the president of Sri Lanka.

(11). We, the assembly, have been turned into a merely deliberative organ.

(12). Truly. As the owner of the world,.....

The text used in this article is a speech delivered by Venezuelan President Hugo Chavez at the 61st United Nations General Assembly, which fiercely criticized US foreign policy.

In 10, 11 and 12, the speaker used focused words such as "merely, a lot, truly"to "highlight the boundaries of the scope of intervention," noting that the original purpose and nature of the United Nations General Assembly had changed. As masters of the world, we must act and expose the use of hypocritical rhetoric by the United States to conceal its paradoxical behaviour.

(13). To Melania and Don and Ivanka and Eric and Tiffany and Barron, I love you and I thank you, and especially for putting up with all of those hours.

This sentence is also from a speech Trump made after he won the general election in the United States on November 9, 2016. In example 13, "especially" uses sharpening techniques in focused resources to stress the hours of suffering before waiting for results to come out, to express himself and his team, to express strong emotions, and to arouse the emotions of the masses.

(14). As my husband has said, the United States is offering many resources as possible to assist in search.

This sentence selected from the speech that Michelle Obama made on the theme of studying abroad at Stanford Center at Peking University. Michelle Obama began her speech by expressing concern about the MH370 crash in 
Malaysia, as well as the U.S. government's sympathy for passengers and members of his family who were unlucky in the crash. And said that the United States government is with them, will work to search for the missing flight MH370.

In the example of 14, the use of the focus fuzzy word "possible" reflects the high life and human rights of the United States. At the same time, the U.S. government has spent as much aid as possible to search for and rescue the missing flight MH370, thereby demonstrating the image of a responsible U.S. power.

\section{CONCLUSION}

Generally speaking, the function of political speech discourse is mostly persuasive, and the speaker's communicative intention is to change the original belief of the audience and urge them to take some actions in order to make them realize the meaning of persuasion. Therefore, most speech languages have the functions of expression, appeal and infection. Graduation makes the speech clear, sonorous and forceful. Using the graduation to analyse political speeches, Finding that the language that is actually hidden behind the ideology of the state. To a great extent, it conveys political strategies and speech skills, achieves the purpose of political speeches, inspires the public, and shapes the good image of the government. At the same time, it also tests the applicability of appraisal theory about this kind of political discourse analysis. It is still in the process of gradual improvement on political discourse, and there are many problems to be solved urgently. In terms of research methods, most of the previous studies used small-scale corpus for text analysis, and the reliability of the analysis still needs to be improved. In addition, there is a broad space for research on the topic of graduation discourse application patterns and genre differences. It provides a new theoretical perspective on political discourse analysis.

\section{REFERENCES}

[1] Bolinger, D. (1972). Degree Words. The Hague \& Paris: Mouton.

[2] Brown P. \& S. Levinson. (1987). Politeness: Some Universal in Language Usage. Cambridge: Cambridge University Press.

[3] Horn, L. (1972). On the Semantic Properties of Logical Operators in English. Ph.D. Dissertatio: University of California.

[4] Hyland, K. (1998). Hedging in Scientific Research Articles. Amsterdam: Benjamins.

[5] Hyland, K. (2000). Disciplinary Discourses: Social Interactions in Academic Writing. London: Longman.

[6] Labov, W. (1984). Intensity. In D. Schiffrin (Eds). Meaning, Form, and Use in Context: Linguistic Applications. Washington, D. C: Georgetown University Press, 43-70.

[7] Lakoff, G. (1972). Hedges: A Study in Meaning Criteria and the Logic of Fuzzy Concepts. Proceedings of the Chicago Linguistics Society, 8: 183-228.

[8] Martin, J. R. (1992a). Macro-proposals: Meaning by Degrees. In W.C. Mann \& S. Thompson (Eds.) Discourse Description Diverse Analyses of a Fund Raising Text. Amsterdam: Benjamins, 359-395.

[9] Martin J. R. (1992b). English Text: System and Structure. Amsterdam: Benjamins.

[10] Martin, J. R. (2000). Beyond Exchange: Appraisal Systems in English. In Hunston, S. \& G. Thompson (Eds.). Evaluation in Text: Authorial Stance and the Construction of Discourse. Oxford: Oxford University Press. 142-175.

[11] Martin, J. R. \& D. Rose. (2003).Working with Discourse: Meaning beyond the Clause. London: Continuum.

[12] Martin, J. R\&P. R. R. White. (2005). The Language of Evaluation: Appraisal in English. London: Macmillan.

[13] Quirk. R, S. Greenbaum, G. Leech. \& J. Svartvik. (1986). A comprehensive Grammar of the English Language. London: Longman.

[14] Sapir, E. (1944). Grading: A Study in Semantics. Philosophy of science, 2, 93-116.

[15] Zhenhua,Wang. (200). Evaluation System and its Operation: a New Development of Systemic Functional Linguistics. Foreign Language. 6,13.

[16] Zadel, L. (1965). A Fuzzy sets. Information and Control. 8, 338-353.

[17] Zhanzi, Li. (2004). Evaluation Theory: Application and Problems in Discourse Analysis. Foreign language Studies.5, 1-6.

Xiaoyan Fan was born in LinFen, China in 1994. She received her undergraduate degree in English from Datong University, China in 2001.

She is currently a graduate student in the School of Foreign Languages and Applied Linguistics, Shanxi Normal University, Linfen, China. 